ARTICULO DE INVESTIGACION

\title{
Agente causal del tizón foliar en Ungnadia speciosa Endl. (Sapindales: Sapindaceae) y la evaluación in vitro e in situ de un biocida
}

\author{
Causal agent of leaf blight in Ungnadia speciosa Endl. \\ (Sapindales: Sapindaceae) \\ and the in vitro and in situ biocide evaluation
}

\begin{abstract}
María Elizabeth Galindo-Cepeda1, Marco Antonio GranilloChapa2, Melchor Cepeda-Siller1, Luis Alberto Aguirre-Uribe1, Francisco D. Hernández-Castillo ${ }^{1}$ y Alberto Flores-Olivas ${ }^{1}$
\end{abstract}

\section{RESUMEN}

\begin{abstract}
La planta llamada regionalmente ojo de venado, también conocida como castaño de México Ungnadia speciosa Endl., es utilizada en programas de forestación en México dadas sus características adaptativas y su forma de vida arbustiva. Sin embargo, su producción en invernadero se ve afectada por patógenos que causan tizones en hojas, achaparramiento y bifurcación de tallos, lo que imposibilita su uso en plantaciones. De ahí que el objetivo del presente trabajo haya sido determinar el agente causal y la evaluación in vitro e in situ del cloruro de benzalconio para su control. Se colectó tejido vegetal en campo e invernadero, se sembró en agar nutritivo y papa dextrosa agar; se realizaron las pruebas preliminares LOPAT y bioquímicas, pertinentes para la identificación. Para la incidencia y severidad, se uso el modelo propuesto por French (1982), la evaluación in vitro fue mediante el método de placa envenenado; usando 13 tratamientos con cinco repeticiones, evaluando las unidades formadoras de colonias (UFC). In situ se usaron siete tratamientos con tres repeticiones, evaluando el área foliar dañada. De acuerdo a los postulados de Koch, se encontró a Pseudomonas syringae, involucrada en el síntoma de tizón y malformaciones del ojo de venado. El cloruro de benzalconio, en todas las dosis controló satisfactoriamente in vitro en todas las dosis; y el mejor tratamiento in situ fue el de 3000 ppm (7 g/L) que presentó un área foliar dañada de 17,33\% y el testigo de 73,09\%.
\end{abstract}

PALABRAS CLAVE:

Cloruro de benzalconio, desierto chihuahuense, ojo de venado o castaño de México, Pseudomonas syringae.

\begin{abstract}
The Mexican buckeye Ungnadia speciosa, is one of the plants used in forestation programs in Mexico due its adaptive features and its shrub or small tree form; however production in the greenhouse is affected by pathogens that cause leaf blight, dwarf and fork stalks, making it impossible to use in plantations. The objective of this work was to determine the causal agent and evaluation of in vitro and in situ of benzalkonium chloride to control it. Plant tissue was collected in field and greenhouse and put in nutrient agar and potato dextrose agar. LOPAT and relevant biochemical test were
\end{abstract}


conducted for identification. For the incidence and severity, the model proposed by French (1982), was used. The poisoned plate flock was used for the in vitro evaluation with 13 treatments and five repetitions, assessing the colony forming units (CFU); seven in situ treatments with three replications were used evaluating damaged leaf area. It was found that for Pseudomonas syringae, according to the Koch's postulates involved in the symptoms of blight and deformities in the Mexican buckeye, field incidence was $12,9 \%$ and $36 \%$ in greenhouse; severity was $6,5 \%$ and $32 \%$, respectively. Benzalkonium chloride satisfactorily controlled in vitro in dosages, and the best treatment in situ was $3000 \mathrm{ppm}(7 \mathrm{~g} / \mathrm{L})$, which showed a leaf damaged area of $17,33 \%$ and target treatment $73,09 \%$.

KEY WORDS:

Benzalkonium chloride, Chihuahuan desert, Mexican buckeye, Pseudomonas syringae.

\section{INTRODUCCIÓN}

El ojo de venado Ungnadia speciosa Endl., es una planta nativa del desierto chihuahuense que se utiliza como planta de ornato, como fuente de néctar para diversas especies de insectos y como planta de cobertura. Esto debido a que requiere de poca cantidad de agua para su establecimiento y supervivencia, así como su rápido desarrollo al ser plantada en suelos poco profundos y/o fértiles. Presenta una floración al inicio de la primavera, por lo que es una fuente de alimento temprana para insectos polinizadores (Burke et al., 1994). Se usa además para disminuir los procesos erosivos, ya que es poco atractiva para los herbívoros (Lipe, 1999).

En México se pierden alrededor de 340000 ha de los recursos naturales en las zonas áridas y los bosques templados (Semarnap, 2005), con sus consecuentes daños al ecosistema. En Coahuila se está trabajando con especies del semidesierto de interés ambiental. Dentro de estas especies se encuentra $U$. speciosa con el fin de mantener la riqueza forestal del país (Banco de semillas forestales de Coahuila, s/f). Sin embargo, uno de los problemas graves para utilizar esta especie, es la falta de plantas de calidad y sanidad adecuadas para su establecimiento en plantaciones.

Dentro de los eventos más comunes en la producción de plantas en viveros y/o invernaderos, destacan las enfermedades, que llegan a ocasionar la pérdida total de lotes o afectar la sobrevivencia de las plantas, las cuales, al ser colocadas en su sitio definitivo tienen menor posibilidad de adaptarse y por lo tanto de prosperar. La producción de plantas sanas es el punto medular para lograr el éxito de las plantaciones. En áreas de distribución natural $U$. speciosa presenta malformaciones, achaparramiento y el tizón en una incidencia baja. En cambio, al producir plantas en invernaderos, donde los factores ambientales se modifican dichas plantas presentan incidencia del tizón de $32 \%$ (Cerezo, 1998). Aunado a esto, la bifurcación del tallo las hace inadecuadas para forestación.

El uso de productos químicos de amplio espectro, es una alternativa para abatir los costos de producción al disminuir la cantidad de agroquímicos usada en la producción de plantas. Uno de estos es el $\mathrm{N}$-alquil dimetil bencil cloruro de amonio, que presenta un amplio espectro de acción sobre diversas especies de microorganismos.

\section{OBJETIVOS}

Los objetivos de este trabajo son: Determinar el patógeno involucrado en el síntoma de tizón del ojo de venado en Ungnadia speciosa, y comprobar el efecto in vitro e in situ de un producto químico de 
amplio espectro, sobre los patógenos aislados de $U$. speciosa.

\section{METODOLOGÍA}

El presente trabajo se realizó en la Universidad Autónoma Agraria Antonio Narro (UAAAN) ubicada en Buenavista, Saltillo, Coahuila, México y se efectuó en dos etapas durante los meses de noviembre 2005 a junio 2006. En la primera, se determinó el agente causal, así como la incidencia y severidad del tizón en campo e invernadero. En la segunda se evaluó un producto biocida in vitro e in situ.

\section{Determinación del agente causal}

En la región noroeste de Coahuila se realizó un recorrido en el área de protección de flora y fauna de Maderas del Carmen, en el municipio de Ocampo, en el cañón denominado El Jardín (INESemarnap, 1997). Ahí se colectó material vegetal con la sintomatología típica del tizón, así como en el invernadero del departamento forestal de la UAAAN. Dicho material se colocó en bolsas de polietileno en una hielera para su traslado al laboratorio de fitopatología del departamento de parasitología, donde fueron procesadas siguiendo la técnica propuesta por Noval (1998). El tejido se sembró en agar nutritivo (AN) y papa dextrosa agar (PDA) ambos marca (Difco). Se incubaron a $25{ }^{\circ} \mathrm{C}$ por 24 horas. De los microorganismos que se desarrollaron se realizó una purificación por explante y estría múltiple en agar nutritivo y se incubaron en las condiciones antes mencionadas. Las cepas bacterianas se sometieron a la tinción de Gram y la prueba de RYO, como primera técnica para separar las bacterias fitopatógenas. Posterior- mente se sembraron en los medios semiselectivos extracto de levadura dextrosa carbonato de calcio (YDC), Perry y Kado $1\left(D_{1} M\right)$, medio $B$ de King (KB) (King et al., 1954), medio Kado y Heskett $\left(D_{3} K\right)$ y medio pectato cristal violeta (CVP), sugeridos por Schaad et al. (2001). A continuación se realizaron las pruebas rápidas de patogenicidad de acuerdo con la técnica mencionada por Rodríguez (2001), usando una concentración bacteriana de $1 \times 10^{-8}$ unidades formadoras de colonias (UFC), de la escala de McFarland. Las pruebas bioquímicas levana, oxidación, pectólisis en papa, arginina (Thornely, 1960) e hipersensibilidad del tabaco (LOPAT), se realizaron de acuerdo al protocolo de cada una de ellas, además de realizar la siembra en el medio semiselectivo agar B de King con antibióticos KBBC, de acuerdo a Ovad et al. (1997).

\section{Incidencia y severidad}

Se trabajó con el modelo de French (1982), en el cual la intensidad es el grado de daño ocasionado en el cultivo, que incluye dos componentes: la incidencia que es el número de plantas afectadas expresado como porcentaje del total, y la severidad que es la porción de tejido afectado, expresado como porcentaje del área total, se propuso la escala siguiente (Tabla 1) para el tizón del ojo de venado $U$. speciosa.

En el invernadero se evaluaron dos lotes de plántulas, cada uno de los cuales contenía mil plantas, en el área de Maderas del Carmen, se recorrió durante cinco días el cañón, encontrando 32 plantas de Ungnadia, a las que se evaluó la incidencia y severidad. 
Tabla 1. Escala de evaluación de la severidad para el tizón del ojo de venado U. speciosa (Galindo y Granillo, 2004).

\begin{tabular}{cc}
\hline Categoría & $\%$ de daño \\
\hline 1 & $<10$ \\
2 & $10-25$ \\
3 & $26-75$ \\
4 & $76-85$ \\
5 & $>85$ \\
\hline
\end{tabular}

\section{Evaluación in vitro}

Se utilizó un diseño completamente al azar (DCA), para la variable unidades formadoras de colonias bacterianas (UFC); por unidad experimental que representa una caja Petri, se evaluaron 13 tratamientos con cinco repeticiones (Tabla 2) del producto comercial Timsen (Okehi group, presentación sales). El método de la evaluación fue el plato envenenado, al que se adicionó el producto al medio de cultivo. El inóculo usado fue $0,1 \mathrm{~mL}$ de solución bacteriana, a una concentración de $1 \times 10^{-4} \mathrm{UFC} / \mathrm{mL}$ de la escala de McFarland, que se dispersó en la caja Petri con la ayuda de una varilla acodada y se incubó a temperatura de 25 ${ }^{\circ} \mathrm{C}$ durante $24 \mathrm{~h}$, en donde se llevó a cabo el conteo de UFC.

\section{Evaluación in situ}

Se utilizó un diseño completamente aleatorio con siete tratamientos y tres repeticiones (Tabla 3). La unidad experimental (UE) fue de nueve plantas de $U$. speciosa. Las plantas utilizadas presentaban cinco hojas y cinco foliolos, así como homogeneidad en el tamaño $(0,90 \mathrm{~m})$ y forma. Las variables consideradas en el experimento fueron: número de lesiones foliares considerando únicamente aquellas que mostraron el tizón característico. La
Tabla 2. Tratamientos usados in vitro contra Pseudomonas syringae.

\begin{tabular}{rl}
\hline Tratamiento & ppm de cloruro de benzalconio \\
\hline 1 & 4000 \\
2 & 3340 \\
3 & 3000 \\
4 & 2670 \\
5 & 2000 \\
6 & 1500 \\
7 & 1000 \\
8 & 500 \\
9 & 250 \\
10 & 180 \\
11 & 70 \\
12 & 120 ppm de sulfato de estrepto- \\
& micina y oxitetraciclina. Testigo \\
13 & comercial \\
\end{tabular}

dimensión de la lesión se expresó en porcentaje de área foliar dañada considerando a la UE como el $100 \%$ del área foliar. Para esto se uso un medidor electrónico de áreas y altura de la planta. Se llevaron a cabo seis aplicaciones cada veinte días del producto comercial Timsen, entre el 18 de diciembre de 2005 y 28 de marzo de 2006. La toma de datos se inició un día antes de la primera aplicación y terminó 20 días posteriores a la última aplicación.

Tabla 3. Tratamientos usados in situ para el control de $P$. syringae.

Tratamiento ppm de cloruro de benzalconio

\begin{tabular}{cc}
\hline 1 & 500 \\
2 & 1000 \\
3 & 1500 \\
4 & 2000 \\
5 & 2500 \\
6 & 3000 \\
7 Testigo & 0 \\
\hline
\end{tabular}


El análisis estadístico de los resultados, se realizó con el promedio general del número de lesiones de tizón foliar, así como del área foliar dañada (\%), en cada uno de los tratamientos y repeticiones, usando un diseño completamente al azar. Los datos se ingresaron al programa estadístico de la Universidad Autónoma de Nuevo León, para correr el análisis de varianza (ANVA) y la prueba de comparación múltiple de medias por el método de Tukey, a $95 \%$ y $99 \%$ de confiabilidad.

\section{RESULTADOS}

Se aislaron de hojas, ramas y tallos los hongos Rhizopus stolonifer (Ehrenb.) Lind. y Penicillium expansum Link, los que se identificaron con las claves morfológicas de Barnett y Hunter (1998), así como la bacteria Pseudomonas syringae van Hall la que fue identificada de acuerdo con las pruebas mencionadas por Schaad et al. (2001); los resultados se muestran en la tabla 4.

Tabla 4. Pruebas preliminares de colonias bacterianas aisladas de U. speciosa.

\begin{tabular}{ll}
\hline Prueba & Resultado \\
\hline Tinción de Gram & $(-)$ bacilos cortos \\
Tinción de flagelos & $(+)$ polares $2-3$ \\
Catalasa & $(+)$ \\
Oxidasa & $(-)$ \\
Prueba de $\mathrm{KOH}$ & $(+)$ \\
Crecimiento en & Aeróbicos estrictos \\
anaerobiosis & \\
\hline
\end{tabular}

Esta bacteria únicamente se desarrolló en el medio B-King y al observar sus colonias con luz ultravioleta con filtro de $420 \mathrm{~nm}$ se presentó una fluorescencia verde-amarillenta, indicando la presencia del género Pseudomonas. En las pruebas rápidas de patogenicidad, en las rodajas de papa no se presentó pudrición y en las hojas de tabaco se observó un tizón con un halo amarillento. Para la diferenciación de las especies se realizaron las pruebas bioquímicas que se citan en la tabla 5. Estos aislados se desarrollaron en el medio KBBC.

Tabla 5. Pruebas bioquímicas y de patogenicidad para diferenciar especies del género Pseudomonas.

\begin{tabular}{ll}
\hline Prueba & Respuesta \\
\hline Levana & $(+)$ colonias pulvinadas \\
Producción del & \\
citocromo oxidasa & $(-)$ \\
Manitol & $(+)$ \\
Sorbitol & $(+)$ \\
Celobiosa & $(-)$ \\
Arabinosa & $(-)$ \\
Sacarosa & $(+)$ \\
Óxido-fermentación & $(+) ;(-)$. \\
Crecimiento a $37^{\circ} \mathrm{C}$ & $(-)$ se incubaron a $35^{\circ} \mathrm{C}$ \\
\hline
\end{tabular}

Los resultados de estas pruebas corresponden a la especie syringae de acuerdo con lo que mencionan Schaad et al. (2001).

\section{Incidencia}

En condiciones de campo, de las 32 plantas que se encontraron en el Jardín de Maderas del Carmen, cuatro presentaron los síntomas de tizón foliar, achaparramiento y malformación, es decir 12,9\%. En el caso del invernadero se analizaron 2000 plantas de las que 720 presentaron estos síntomas, es decir $36 \%$ se encontraron dañadas.

\section{Severidad}

El área foliar dañada en campo fue de $6,5 \%$ es decir, en la categoría uno de la escala de evaluación. En el invernadero 
la media aritmética obtenida fue de $32 \%$, ubicándose en la categoría tres de la escala de evaluación utilizada, como se observa en la figura 1.

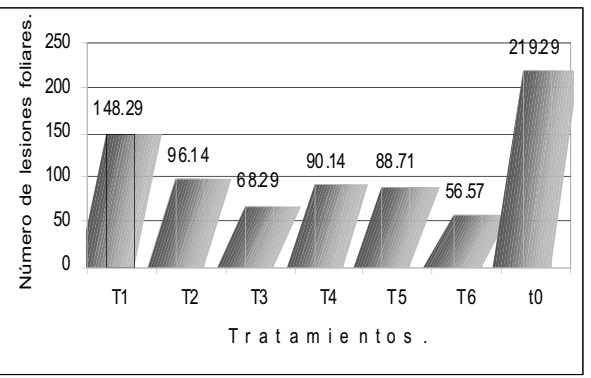

Figura 1. Número de lesiones de Pseudomonas syringae sobre Ungnadia speciosa.

\section{Pruebas in vitro}

Fueron 11 las dosis de cloruro de benzalconio usadas contra $P$. syringae, desde 70 ppm hasta 4000 ppm $(0,005-1,3 \mathrm{~g} / \mathrm{L}$ producto comercial), en las cuales no existió la formación de unidades formadoras de colonias bacterianas a las $24 \mathrm{~h}$; así como tampoco en el tratamiento comercial usado como testigo que fue el sulfato de estreptomicina y clorhidrato de oxitetraciclina que contenía 120 ppm (1 $\mathrm{g} / \mathrm{L}$ producto comercial). En el tratamiento testigo absoluto se reportó un promedio de $1720 \mathrm{uFC} / \mathrm{mL}$.

\section{Pruebas in situ}

El comportamiento de los tratamientos del cloruro de benzalconio en el número de las lesiones foliares de la bacteria $P$. syringae, se muestra en la tabla 6 .

El análisis de varianza, indica que existe una diferencia altamente significativa entre los tratamientos, como se observa en el promedio general del número de lesiones del área foliar, el tratamiento siete ( $\mathrm{T}_{7}$ testigo), presentó un promedio de lesiones de 73,09; mientras el que fue el mejor, tratamiento seis ( $T_{6}, 3000$ ppm, 7 $\mathrm{g} / \mathrm{L}$ de producto comercial) presenta 18,85 lesiones (Figura 2); seguido del tratamiento tres $\left(T_{3}, 1500\right.$ ppm) con 22,76 lesiones por área foliar. La prueba de comparación múltiple de medias por el método de Tukey arrojó tres categorías en los dos niveles de confiabilidad, pero en donde se usó el

Tabla 6. Número de lesiones del tizón

en el área foliar de $U$. speciosa afectada por Pseudomonas syringae.

\begin{tabular}{|c|c|c|c|c|c|c|}
\hline $\begin{array}{c}\text { Tratamiento } \\
\mathrm{ppm}\end{array}$ & Rep. 1 & Rep. 2 & Rep. 3 & Promedio & $\begin{array}{c}\text { Tukey } 95 \% \\
(\mathrm{DHS}=22,62)\end{array}$ & $\begin{array}{l}\text { Tukey } 99 \% \\
(\mathrm{DHS}=28,47)\end{array}$ \\
\hline T1 500 & 46,0 & 52,14 & 50,14 & 49,42 & $26,81 \quad$ B & 20,95 B C \\
\hline T2 1000 & 19,57 & 36,43 & 40,14 & 32,04 & 9,43 A B & $3,57 \mathrm{AB}$ \\
\hline T3 1500 & 22,14 & 23,86 & 22,29 & 22,76 & $0,14 \mathrm{~A}$ & $-5,72$ A B \\
\hline T4 2000 & 28,57 & 36,14 & 25,43 & 30,04 & 7,43 A B & $1,57 \mathrm{AB}$ \\
\hline T5 2500 & 22,86 & 24,14 & 41,71 & 29,57 & 6,95 A B & $1,09 \mathrm{AB}$ \\
\hline T6 3000 & 21,86 & 15,86 & 18,86 & 18,85 & $-3,77 \mathrm{~A}$ & $-9,61 \mathrm{~A}$ \\
\hline T7 testigo & 58,14 & 84,00 & 77,14 & 73,09 & $50,47 \quad C$ & $44,62 \mathrm{C}$ \\
\hline
\end{tabular}




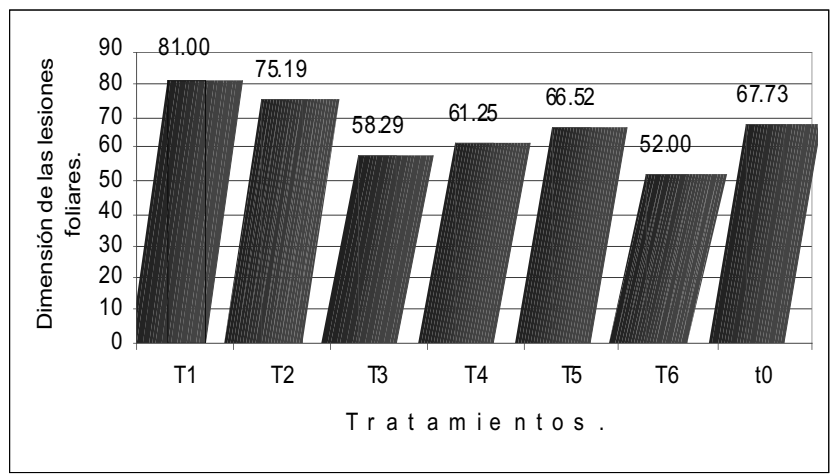

Figura 2. Porcentaje o dimensión de lesiones de Pseudomonas syringae usando cloruro de benzalconio.

cloruro de benzalconio todos son iguales estadísticamente, el único diferente fue el testigo ya que es el que presenta el número más grande de lesiones.

\section{Dimensión de las lesiones}

El área foliar total dañada, muestra que hay diferencia entre los tratamientos. Sin embargo en la prueba de Tukey a $95 \%$ (DHS), se observan dos niveles de significancia, lo que estadísticamente nos dice que todos los tratamientos son iguales. El mejor tratamiento fue el seis (3 000 ppm, $7 \mathrm{~g} / \mathrm{L}$ de producto comercial) con $7,89 \%$ de área foliar dañada por $P$. syringae, mientras que el testigo $\left(T_{7}\right)$ $13,14 \%$ de daño; sin embargo los tratamientos uno y dos $\left(T_{1}, 500\right.$ ppm y $T_{2}, 1$ $000 \mathrm{ppm}$ ), presentaron mayor área foliar dañada por el tizón que ocasiona esta bacteria (Tabla 7).

La variable altura de la planta no presentó diferencia significativa en los tratamientos usados.

Tabla 7. Dimensión del área foliar dañada de $U$. speciosa por la bacteria $P$. syringae, expresada en porcentaje.

\begin{tabular}{|c|c|c|c|c|c|}
\hline $\begin{array}{c}\text { Tratamiento } \\
\text { ppm }\end{array}$ & Rep. 1 & Rep. 2 & Rep. 3 & Promedio & Tukey 95\% (DHS= 9,44) \\
\hline T1 500 & 32,21 & 27,43 & 21,37 & 27,00 & 17,56 \\
\hline T2 1000 & 23,64 & 30,57 & 20,98 & 25,06 & $15,63 \mathrm{AB}$ \\
\hline T3 1500 & 17,25 & 19,52 & 21,51 & 19,39 & 9,99 A B \\
\hline T4 2000 & 20,97 & 21,22 & 19,06 & 20,41 & 10,98 A B \\
\hline T5 2500 & 19,52 & 22,51 & 24,49 & 22,17 & $12,74 \mathrm{AB}$ \\
\hline T6 3000 & 18,18 & 18,17 & 15,73 & 17,33 & 7,89 A \\
\hline T7 testigo & 24,33 & 24,81 & 18,59 & 22,57 & $13,14 \quad B$ \\
\hline
\end{tabular}




\section{DISCUSIÓN Y CONCLUSIONES}

Rhizopus stolonifer y Penicillium expansum son hongos que causan pudriciones en tejidos suculentos de frutas y hortalizas durante el almacenamiento y transporte, además de considerarse hongos contaminantes en los laboratorios de acuerdo con Smith et al. (2001), por lo que no presentaron una relación con los síntomas causados por el tizón foliar en $U$. speciosa. Pseudomonas syringae es una bacteria que causa disminución en el crecimiento, marchitamiento y defoliación del follaje así como la aparición de grietas y necrosis en el floema en plantas de olivo (Scortichini, 1997). En el ojo de venado $U$. speciosa, los síntomas del tizón foliar inician en el ápice de las hojas hacia la base, seguido de una defoliación, donde el tallo de las plantas se torna quebradizo con grietas y disminuye su crecimiento (Figura 3). Las pruebas bioquímicas y de patogenicidad que se realizaron a las cepas, nos indican que el género Pseudomonas únicamente fermenta la glucosa y en condiciones aeróbicas forma un ácido que cambia el $\mathrm{pH}$ del medio, que se manifiesta como un cambio de color, esto de acuerdo con Hugh y Leifson (1953). Este género presenta una respuesta positiva a la presencia de la enzima citocromooxidasa por lo que permite separarlo de otros géneros (Lelliot et al., 1966). Las colonias que crecieron en la levana fueron pulvinadas, por lo que el grupo syringae de Pseudomonas es el único que aprovecha este polisacárido y el grupo fluorescente no lo aprovecha (Schaad et al., 2001). La cepa bacteriana se desarrolló en el medio semiselectivo $\mathrm{KBBC}$ en el cual pueden desarrollarse los patovares syringae, pisi y tomato de acuerdo con Ovad et al. (1997). Para confirmar el patovar, la capacidad para formar núcleos de hielo serviría para separar syringae y pisi de tomato ya que éste no los forma; y el patovar syringae de la pisi con la prueba DL homoserina, debido a que la respuesta del primero es negativa y la del segundo positiva.

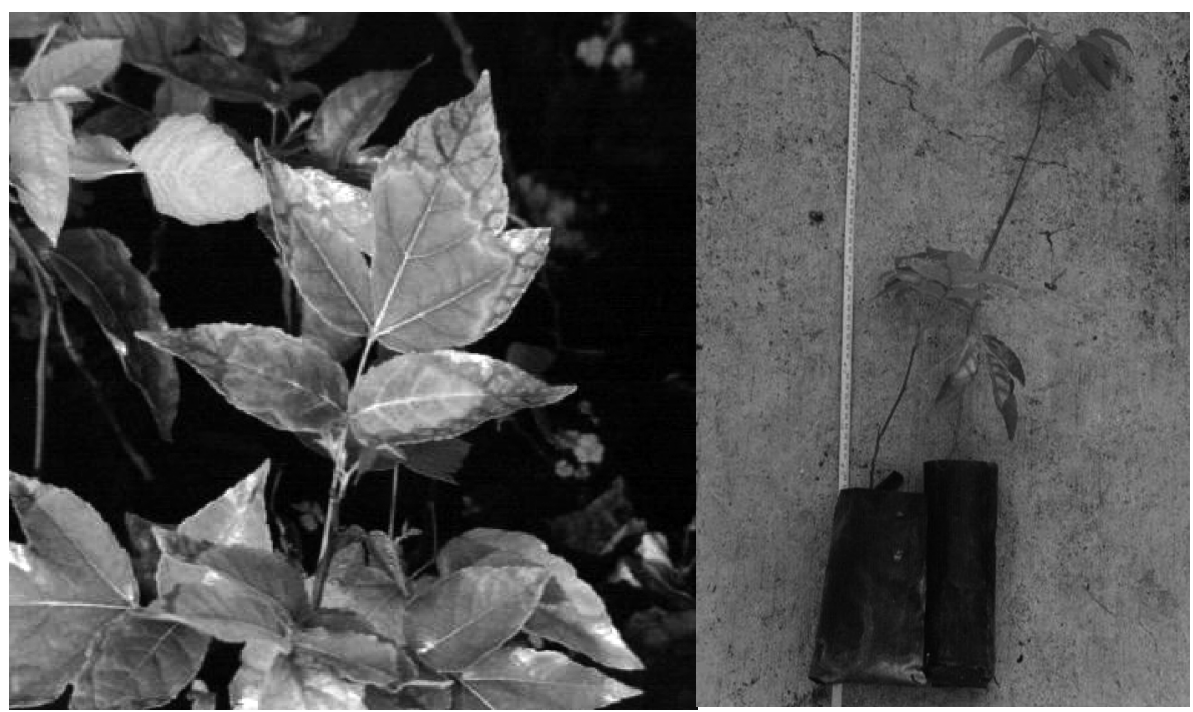

Figura 3. Daño de Pseudomonas syringae sobre hojas y plantas de U. speciosa. 
Las plantas de $U$. speciosa en el invernadero presentaron $36 \%$ de incidencia de tizón y malformaciones por lo que no pueden ser usadas en reforestación, ya que los técnicos de Comisión Nacional Forestal (INE-Conafor) al evaluar la calidad fitosanitaria de las plantas únicamente aceptan lotes con $20 \%$ de daño (González, 2004).

Las diferentes dosis in vitro de cloruro de benzalconio no permitieron el crecimiento bacteriano. Esto coincide con lo que reportan investigaciones de Ohio State University (1997), en donde usaron 620 ppm de cloruro de benzalconio en placas de papa dextrosa agar, y no existió la formación de UFC de las bacterias Erwinia carotovora, Agrobacterium tumefaciens y Xanthomonas campestris. Esta misma dosis se uso in vitro y campo para controlar al hongo Alternaria spp., que afecta a la planta Tagetes erecta L., en donde se logró $85 \%$ de inhibición del crecimiento del hongo in vitro y de $73 \%$ en campo (Robert, 2000). Este producto no muestra una buena acción para eliminar bacterias esporógenas como Bacillus subtilis cuando se usa una concentración de $0,5 \mathrm{mg} / \mathrm{mL}$ (Acosta et al., 2001), la bacteria Pseudomonas syringae no forma este tipo de estructura de resistencia sino que sobrevive a condiciones adversas en restos de tejido vegetal y cánceres de la planta, por lo que debe destruirse y aplicarse el producto de manera preventiva. El cloruro de benzalconio al usarse in situ a dosis de 3000 ppm $(7 \mathrm{~g} / \mathrm{L})$ en plantas de $U$. speciosa, éstas presentaron $7,89 \%$ del área foliar dañada por la bacteria, el testigo 13,14\%. Esto coincide con lo que mencionan Rodríguez y Jiménez (1999), al evaluar el Timsen contra Colletotrichum gloeosporioides en mango encontraron que el área del fruto fue de $6,98 \%$ al usar una dosis de 400 ppm una sola vez, contra el testigo que presentó $14 \%$ de área dañada; lo mismo encontraron Páez y Peña (2000) en mango contra este mismo hongo, a dosis de 620 ppm el área que presentó daño fue de $7,0 \%$ y en el testigo de $21 \%$.

La bacteria $P$. syringae es la causante del síntoma tizón foliar que presenta el huésped comúnmente llamado ojo de venado $U$. speciosa, en campo presenta un $12,9 \%$ de incidencia y en invernadero de $36 \%$; la bacteria es controlada por las 11 dosis de cloruro de benzalconio ( 0,005-1,3 g/L) in vitro ya que no presentó la formación de UFC. El mejor tratamiento in situ para controlar el tizón en el ojo de venado en invernadero fue de 3000 ppm ( $7 \mathrm{~g} / \mathrm{L})$, en donde presentó un daño foliar de $17,33 \%$.

\section{REFERENCIAS}

Acosta, E., A. Herrera y V.H. Mata. 2001. El cloruro de benzalconio. Salud Pública de México 43(6):499-573.

Barnett, H.L. y B.B. Hunter. 1998. Illustrated genera of imperfect fungi. 4a. ed. APS Press. 218 p.

Burke, H.R., J.A. Jackman y M. Ose. 1994. Insects associated with woody ornamental plant in Texas. Texas A\&M University. Department of Entomology. h t t p : / / en tow w w . tamu . edu / extension/publications/woody.html

Cerezo, H.V. 1998. Identificación de microorganismos presentes en Azalea spp., Gardenia jasminoides, Ungnadia speciosa así como el control químico de bacterias in vitro. Tesis de licenciatura. UAAAN, Saltillo, Coahuila, México. $53 p$.

Coahuila, Banco de Semillas Forestales (s/f). http://www.coahuilatransparente. gob.mx/boletines/documentos-boletines/publicaciones $\%$. 
French, R.E. 1982. Métodos de investigación fitopatológica. Instituto Interamericano de Cooperación para la Agricultura. Costa Rica. 132 p.

González, C.A. 2004. Comunicación personal. Técnico Conafor Región VI Río Bravo. Saltillo, Coahuila, México.

Hugh, R. y E. Leifson. 1953. The taxonomic significance of fermentative versus oxidative metabolits of carbohydrates by various Gram-negative bacteria. L. Bacterial 66:24-26.

Instituto Nacional de Ecología-Secretaría del Medio Ambiente Recursos Naturales y Pesca (INE-Semarnap). 1997. Programa de manejo del área de protección de flora y fauna Maderas del Carmen. 1a. ed. México. 512 p.

King, E.O., M.K. Ward y D.E. Raney. 1954. Two simple media for the demonstration of pyocyanin and fluorescein. J. Lab. Clin. Med. 44:301-307.

Lelliot, R.A, E. Billing y A.C. Hayward. 1966. A determinative scheme for fluorescence plant pathogenic bacteria. J. Appl. Bact. 29:470-478.

Lelliot, R.A. y D.E. Stead. 1987. Methods for diagnosis of bacterial disease of plants. Methods in plant pathology. Ed. T. F. U., Preece Vol. 2, Blackwell Scientific Publications Oxford, pp. 100-200.

Lipe, J.A. 1999. Deer resistent landscape plants. The Texas A\&M University System. http://www.tpoint.net/ neighbor/Deer.html.

Noval, A.C. 1998. Bacterias. Dirección General de la Sanidad de la Producción Agrícola. Manual de laboratorio. Diagnóstico de hongos, bacterias y nemátodos fitopatógenos. Madrid, España, pp. 118-148.
Ohio State University. 1997. Timsen research summary report. $5 \mathrm{p}$.

Ovad, V., K. Rudolph y K. Krohn. 1997. Serological classification of Pseudomonas syringae pathovares based on monoclonal antibodies towers the lipopolisaccaride O-chains, pp. 526-531. In, Rudolph, K., T. J. Burr, J. W. Mansfield, D. Stead, A. Vivian y J. von Kiestzell, eds. Developments in plant pathology, vol. 9: Pseudomonas Syringae pathovares and related pathogens. Kluwer Academia Publishers. Boston. $546 \mathrm{p}$.

Páez, R.A. y R. Peña. 2000. Manejo de antracnosis Colletotrichum gloeosporioides (Penz) en la fase de poscosecha en mango c.v Vallenato. Patología de Frutas Tropicales y Poscosecha, Abstracts of the 46th annual meeting of the Interamerican Society for Tropical Horticulture, Miami FI. EUA, pp. 112-115.

Rodríguez M., M.L. 2001. Manual para la identificación de bacterias fitopatógenas. UACh. Chapingo, Edo. de México. $119 \mathrm{p}$.

Rodríguez, N.S. y C. Jiménez. 1999. Efecto de benzoato de sodio y timsen en el control de Colletotrichum gloeosporioides en frutos de mango. Resúmenes de los trabajos presentados en XVI Congreso Venezolano de Fitopatología. Barquisimeto,Venezuela. 72 p.

Robert, R. 2000. Identification and control of foliar spot pathogen in Tagetes erecta L. National Agricultural University, La Molina Phytopatolgy Speciality. Lima, Perú. 36 p.

Schaad, N.W., J.B. Jonas y W. Chun. 2001. Laboratory guide for identification of plant pathogenic bacteria. 5a. ed. APS Press. Minnesota, EUA, 373 p. 
Scortichini, M. 1997. Pseudomonas syringae pv syringae associated with decline in olive due to excess of magnesium. Informatore Fitopatologico 47(12):47-50.

Semarnap. 2005. Programa forestal y de suelo 1995-2000. Comisión Nacional Forestal. Gerencia de Geomática. México, D.F.
Smith, I.M., J. Dunez, D.H. Phillips, R.A. Lelliot y S.A. Arched. 2001. Manual de enfermedades de plantas. Ed. Mundi Prensa. $671 \mathrm{p}$.

Thornley, M.J. 1960. The differentiation of pseudomonas from other Gram-negative bacteria on the basis of arginine metabolism . J. Appl. Bacteriol. 23:2752. 